was a great help : so, also, his independent but moderate fortune, free from family demands; for he was childless, and survived his wife. Of a philosophical temperament, and quite exempt from personal ambition, he might have been expected to take life easily; but noblesse oblige ruled his spirit, and he gave himself with unremitting and most disinterested devotion to his chosen line of work from boyhood to old age. $\mathrm{He}$ never seemed to select easy or congenial work, as he might have done, but rather took upon himself the harder tasks. Whatever he put his hand to was done faithfully; and, large as were his undertakings, he had the rare merit and good fortune of having completed all that he undertook. Hardly ever had a naturalist such a wellrounded life. Thirty years

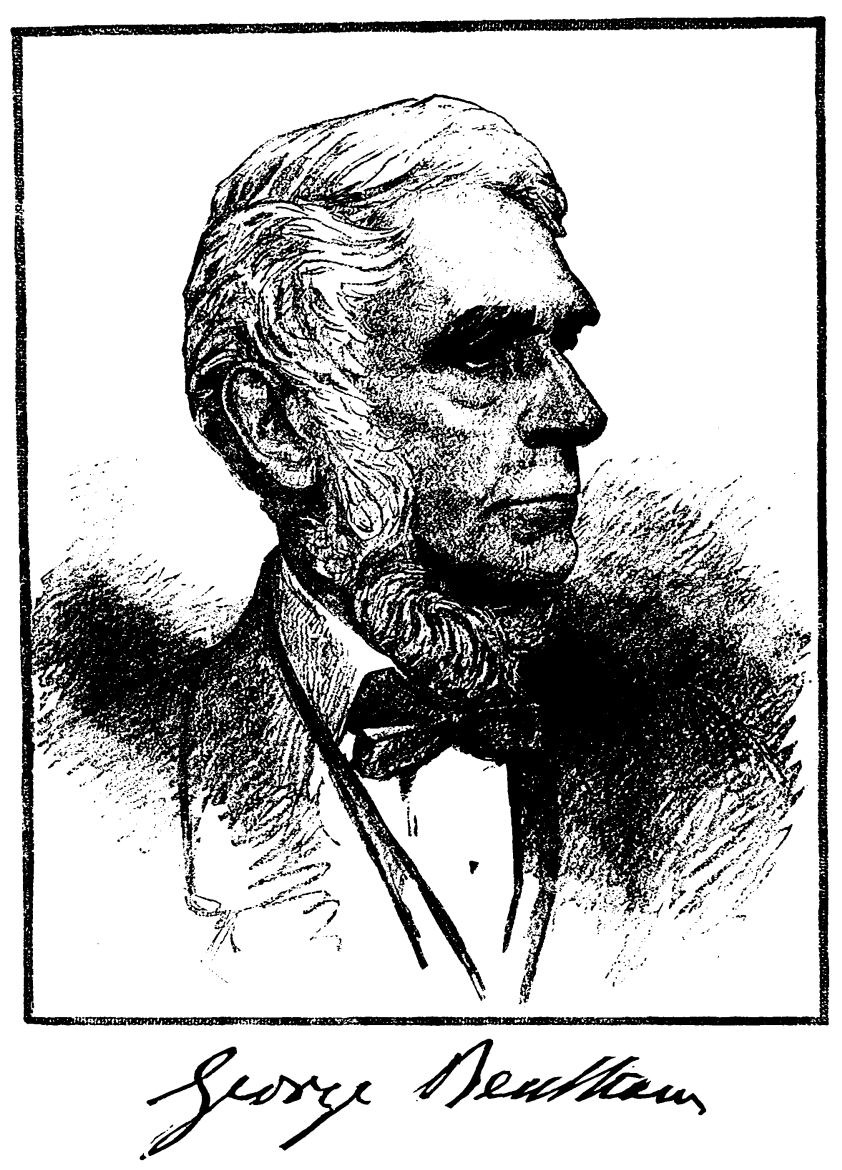
ago he gave

to Kew his herbarium and library ; and there, though living in London, he set up his study, in near association with his colleague and dearest friend, the director, in an apartment which will seem desolate enough now that he is gone. There he might be found at his work from ten to four o'clock during five or six days of every week ' with the regularity of a bankclerk.' Neither biographical details nor an analysis of the work of Mr. Bentham are here attempted. These may be deferred to another occasion. But this simple tribute to a revered memory ought not to close without a word which may bring the reader nearer to the man. It might be thought that because Bentham was unusually reserved, and averse to popularity, he was of a cold and unsympathetic nature. It was not so. Rather, it was shyness, and a desire to save his time, that kept him aloof, and gave him an air of dryness. He was fond of the society of his intimate friends when the work of the day was over; and his attachments, if not numerous, were warm and true. All who really knew him will remember him as one of the most kindly, sweet-tempered, and generoushearted of men.

The accompanying likeness, from one of the few photographs which were ever taken of him, represents Mr. Bentham at about the age of fourscore.

A. G.

\section{EDUCATION AT THE INTERNATIONAL HEALTH EXHIBITION, LONDON.}

As a member of the general committee of this exhibition, as well as of the chief educational jury thereat, the present writer has been requested by the conductors of Science to give some account of the educational exhibits on 
view there (several of which will, at its closing, be despatched to the New Orleans exhibition); as well as of the international conference on education, - the first ever held, - which was opened on Monday, Aug. 4.

The present exhibition (called the 'Healtheries') is on the site of the 'Fisheries' of last year; but more than two acres of additional buildings have had to be constructed for it, and portions of the Royal Albert hall, as well as of the newly erected City and guilds of London institute, have been pressed into the service also, mainly to afford room for some of the educational exhibits. It is probably not too much to say, that no such elaborate and extensive collection of educational appliances, methods, and results has ever been brought together before ; notwithstanding the fact, that, the primary object of the whole exhibition being to elucidate the conditions of health, it was considered expedient to attach to the principal display, mainly such objects and appliances as had a special relation to healthful school life. This limitation, however, has been interpreted somewhat liberally ; and the result is a collection in which can be studied and compared the educational systems in primary, general, and technical education as practised in the British Islands, France, and Belgium, and to a less extent in Germany, Sweden, Switzerland, the United States, and Canada. At a meeting of the jurors held early in June, at which the Prince of Wales presided, the eminent surgeon Sir James Paget delivered an admirable address on 'National health and work,' in the course of which he estimated (as the result of carefully compiled statistics) that the annual loss to the English nation from sickness, four-fifths of which was preventable, amounted to the work that twenty million men would do in a week. He also pointed out the close relations between education and health, and closed with a very eloquent aspiration for the creation of a sound public opinion that physical health, just as intellectual superiority and martial prowess, was a thing to be striven after.

The exhibition itself has been a very great success ; the attendance having been about onethird more than at the Fisheries, and averaging about one hundred and forty thousand visitors per week. The musical attractions have been great, as well as those of the illuminations of the grounds and buildings. The electric-lighting display is on a much larger scale than on any previous occasion, many thousands of incandescent and hundreds of arc lamps being employed; and the perfect steadiness of the latter exceeds any thing that has yet been seen. At the weekly Wednesday-evening fêtes the effects obtained by the illumination of fountains by electric lights in various ways (a prominent one being the total reflection of a beam of light within a jet of water, on the principle of the well-known lecture experiment) are exceptionally beautiful, and perhaps can best be compared to showers of various-colored gems.

The educational portion of the exhibition was opened by the Prince of Wales, about the middle of June; and its contents form the subject of a closely printed catalogue of several hundred pages, some of which are filled with admirable summaries and digests of the work accomplished by various edncational organizations, - such, for example, as those of the ministers of public instruction in France and Belgium, both of which governments have organized elaborate collective exhibitions showing the methods and results of their primary and secondary education. Education in France has lately made most rapid advances; for the money which no previous government could obtain for popular education, the parliament of the third republic, definitely consolidated in 1877 , has not feared to demand of the state, notwithstanding the pressure of taxes from the foreign and civil wars of 1870 . In 1882-83 there were $5,432,151$ pupils, and 129,657 teachers (of whom only 21,781 were uncertificated), in primary schools in France; and the general outlay of the state for primary education in that year amounted to very nearly $\$ 20$,000,000. In March, 1882, laws were passed which rendered obligatory, $1^{\circ}$. the teaching of the elementary physical sciences in primary schools, $2^{\circ}$. the performance therein of a certain amount of manual work. Accordingly we find exhibited by the French minister of public instruction the authorized collections of objects and apparatus used in this teaching, as well as models of simple and cheap apparatus such as could be fabricated by the pupils themselves. The second law has called into existence the 'Ecole normale de travail manuel,' a school probably unique, in which the whole instruction is gratuitous, admission being by competitive examination; and its course comprises the systematic teaching of carpentry, the use of the lathe, the chemical and physical laboratory, the smith's forge, and the engineer's shop. The handicraft work of pupils in many of the French primary schools, as well as in several technical schools, is very remarkable; while in the department of agricultural industry, the work of schools at Lille, 
and also at Beauvais, is much to be commended and worthy of imitation. In the Belgian court, the systematic methods and good gradation of the school work are very remarkable; and very great prominence is given to the objective method of teaching in almost every subject. The technological and other school museums (notably that at Verviers) the contents of which are collected by the pupils, deserve especial notice, as also the whole apparatus for handicraft teaching.

The collective exhibit of the Institute of the brothers of the christian schools (which will be sent en masse to New Orleans) is one of the most remarkable and interesting in the whole Erlucational exhibition. Founded in Paris in 1680 by the venerable Dr. J. B. de la Salle, the institute has now nearly 12,000 brothers, distributed over 13 countries, directing 1,200 schools with an attendance of about $330,00.0$ boys. Following everywhere the same general methods of teaching, they modify their details according to the requirements of the country in which they are ; for example, in their UnitedStates schools, every boy is taught, $1^{\circ}$. shorthand writing, $2^{\circ}$. the Morse alphabet, $3^{\circ}$. the use of the type-writer. The results of their teaching, as exhibited in ' $\mathrm{sworn}$ ' performances of their pupils, in some instances excelled any thing known to the jury of experts who reported thereon. One of their specialties is their system of models, maps, etc., for teaching geography : they were the first hypsometrical maps published in French, or, for school use, in any language; and they are intended to give, by a suitable arrangement of colors, clear notions of the real configuration of the earth's surface. The objective and demonstrative methods of teaching are slowly finding their way into English schools, especially the 'boardschools' of Birmingham, Liverpool, Leeds, etc. But it may perhaps be permitted to the writer to say, as the result of a very close examination (extending over more than a week continuously) of the exhibits relating to primary education in various countries, that one important lesson to be learnt from the comparison of continental methods of instruction with English (and, so far as his knowledge extends, the same remark applies to America) is the great advantage afforded by that objective system, and by the adoption of that systematic order and method in all subjects of instruction, literary or otherwise, to which the name scientific, in the highest and best sense of the term, is applicable. This system is really a continuation of nature's method of instruction, and should be commenced in the earliest years.
The late Dr. Whewell, in congratulating a friend, famous for his knowledge and ability, on the birth of a son, remarked, ' Young as he is, he will learn more than you in the next twelve months!' Accordingly we find in this exhibition, that the increased attention now being devoted to the whole subject of infant training, and the enlarged sympathy and interest with which the best modern teachers are studying the methods of Fröbel (some of the developments of which are at the basis of all so-called technical training), have justified the appropriation of a very considerable space to illustrations of the methods and results of the kindergarten system.

The limits at our disposal permit of no more than a reference to the appliances and results of technical schools, and of elementary artinstruction, nor to special methods and apparatus used in educating the blind and the deaf and dumb, nor to exhibits which illustrate such important subjects as every thing relating to the structural arrangements of school-buildings, school-kitchens, sanitaria, school-infirmaries, and lastly, though by no means least in importance, the gymnastic and other apparatus for physical training in schools. An allusion may be perhaps expected to the controversy now going on in England about overwork in schools. Probably the best answer to the alleged overwork is the fact, given on the authority of Sir Lyon Playfair, that, in the ten years succeeding the passing of the compulsory-education act, the health of children between five and fourteen years of age was thirty-three per cent better (as evidenced by the death-rate) than in the previous ten years ; while the health of children under five years old only improved five per cent in the same period. Investigation has shown that almost every case of over-strain occurs in poor districts (both in town and country), where the children are underfed, a piece of bread being often their only midday meal.

It has been the aim of the writer, to draw attention to the growing recognition of the importance of objective methods of teaching. This may almost be said to have been the keynote of the International conference on education (Aug. 4 to 9 inclusive), which the president, Lord Reay, the rector of the University of St. Andrews, struck in his opening address. In a very able and scholarly discourse, he traversed a very wide educational area; but the point which drew forth the greatest applause was the expression, in regard to primary education, of his hope that the reign of the three $R$ 's (reading, (w) riting, and (a) rithmetic) 
would speedily be replaced by that of the three D's, - drill, drawing, and (a)droitness. At the close, Mr. J. R. Lowell, the American minister, speaking as an ex-professor of Harvard, moved a vote of thanks; which was seconded (in French) by Mr. Buisson, director of primary education in France. Mr. Auguste Couvreur of Belgium supported the motion; thanking also Lord Carlingford and Mr. Mundella, the English government representatives of the education department, for their presence there that day. There were about fifty foreign delegates from twelve countries (including Japan and Brazil), attending this conference, the proceedings of which will be published in the course of the autumn. The conference, after being opened by Lord Reay, divided itself into four sections, which sat simultaneously from ten to one and from two to five for five days; and we conclude this article with a list of some of the more important subjects on which papers were read and discussed. $1^{\circ}$. The conditions of healthy education; $2^{\circ}$. Infant training and teaching; $3^{\circ}$. Technical teaching of all kinds (by Professor Woodward, St. Louis, U.S.A., among others) ; $4^{\circ}$. The methods of teaching the different branches of physical and natural science in elementary and other schools; $5^{\circ}$. The teaching of music; $6^{\circ}$. Museums, libraries, etc.; $7^{\circ}$. Training of teachers $; 8^{\circ}$. Inspection and examination of sohools $; 9^{\circ}$. Organization of elementary education; $10^{\circ}$. Organization of intermediate and higher education; $11^{\circ}$. Organization of university education; $12^{\circ}$. On the teaching of agricultural science.

William Lant Carpenter.

\section{RAILWAY-SIGNALS AT THE ELEC- TRICAL EXHIBITION.}

Among the interesting features of the Electrical exhibition are the different systems of automatic electric railway-signals, designed to render collisions and wrecks impossible. One system, already in quite extensive use, is there illustrated in its application to the running of trains on the block system, on both single and double tracks, to the approaches of a crossing of two roads at the same grade, and to various combinations of switches and signals, whereby a signal cannot be set so as to 'clear' a train until the switch has first been turned in the proper direction, and by this very motion has automatically unlocked the signal-lever. If through any obstruction or failure in the connections the switch is not thrown clear over to its proper position, the automatic electric unlocking action will not respond, and the signal cannot be turned to let the train proceed. The application to a crossing of two roads at grade is very ingenious. The four approaches are guarded by switches, always left open when not in use; so that a runaway locomotive, or other destructive intruder, would be switched round upon a side curve, out of harm's way, as far as the crossing is concerned; and the signals are locked fast at 'danger' as long as these switches are open. Upon the approach of a train from any of the four directions, it announces itself in the signal-house while still at a considerable distance; and then, if the crossing is clear, and there is no previous announcement from either of the other three directions, the signal-man in his lookout-house turns a lever, which, by pneumatic action, closes the switch for the approaching train. This same levermotion locks all the other switches open; so that the man could not, if he would, let any other train approach the crossing till this one had passed. If the switch closes safely, an automatic electric circuit unlocks the danger-signal lever for this one switch. The man then turns it, and then clears the track for the oncoming train, which can thus pass safely without stopping. If trains approach, meanwhile, from other directions, the danger-signals and open switches which the signal-man himself cannot unlock till the train has passed the switch beyond the crossing, and automatically unlocked them - prevent any other train from getting to the crossing.

In running upon the block system, it is so arranged that a train entering upon each section, automatically closes there a green warning-signal and a red danger-signal for any following train. As it leaves the section, it automatically signals back, and opens the red danger-signal, but leaves the green warningsignal till it has left the next section, two blocks ahead. The action of a train, then, in leaving one section and entering on another, is to set the two signals there, and to signal back one block to open the red signal, and two blocks to open the green. The engineer of a following train, upon seeing a green signal, will know that a train is somewhere on the section next but one ahead of him, and will run cautiously; and if, upon reaching the next signal, he finds both the green and the red, he must stop till the train ahead has opened the red one. Upon a single-track road a similar set of signals is given, on the other side of the track, for two blocks ahead as well as behind the train. The automatic train-signals are all given through pairs of insulated rails, across which any pair of car-wheels will close an electric circuit; and they are so arranged, that, if the battery fails, the signal goes to danger through the action of gravity, and so remains till the trouble is remedied. This system depends principally, for safety, upon the watchfulness and certainty of the engineer in reading the signals correctly.

Another company exhibits a system which in some respects is superior to this in avoiding the danger from sleepy or inattentive engineers, or from the difficulty of reading the signals in stormy or foggy weather, and the trouble from batteries giving out or getting weak. Each locomotive carries its own battery in the shape of a dynamo, driven constantly by a small steam-en- 